\title{
COVID-19 Pandemic through the Lenses of Nurses and Midwives in Zambia: Exploring Depression, Anxiety and Stress
}

\section{Lonia Mwape1, Kestone Lyambai2 ${ }^{2}$, Esther Chirwa1, Mavis Mtonga1, Patricia Katowa-Mukwato², Agatha Lloyd ${ }^{3}$}

${ }^{1}$ School of Nursing Sciences, Levy Mwanawasa Medical University, Lusaka, Zambia

${ }^{2}$ School of Nursing Sciences, University of Zambia, Lusaka, Zambia

${ }^{3}$ Lusaka District Health Office, Lusaka, Zambia

Email: *kestone.lyambai@unza.zm

How to cite this paper: Mwape, L., Lyambai, K., Chirwa, E., Mtonga, M., Katowa-Mukwato, P. and Lloyd, A. (2022) COVID-19 Pandemic through the Lenses of Nurses and Midwives in Zambia: Exploring Depression, Anxiety and Stress. Open Journal of Psychiatry, 12, 11-22. https://doi.org/10.4236/ojpsych.2022.121002

Received: August 17, 2021

Accepted: November 22, 2021

Published: November 25, 2021

Copyright $\odot 2022$ by author(s) and Scientific Research Publishing Inc. This work is licensed under the Creative Commons Attribution International License (CC BY 4.0).

http://creativecommons.org/licenses/by/4.0/

\begin{abstract}
Following the declaration of COVID-19 as an international health emergency, Zambia like many other countries implemented measures to limit human interaction and curb the spread of the disease. In the midst of these measures, nurses and midwives continue to provide care to suspected and confirmed cases of COVID-19, which puts them at risk of contracting the disease and compromising their psychological wellbeing. The aim of this study was to assess the levels of depression, anxiety, and stress experienced by nurses and midwives working in health facilities in two districts of Zambia during the COVID-19 pandemic. This descriptive cross-sectional study involving 187 nurses and midwives was conducted between July and December 2020 in selected health facilities in Lusaka and Chilanga Districts. The Depression Anxiety and Stress Scale (DASS) 21 was used to collect the data which was analysed using univariate analysis. Majority of the respondents were female (84\%) and mean age at 30.1 (SD 9.05) years, 58.3 percent were married, and 50.84 percent had children. The mean work experience was 6.63 (SD 4.75) years, and 54 percent had worked for less than five years. Overall, 22.5 percent of nurses and midwives reported depression, 52.4 percent had anxiety and almost half (42.2\%) had varying levels of stress. Anxiety and stress correlated significantly with working in COVID Isolation departments $(\mathrm{P}=0.001)$. Strategies such as strict adherence to infection prevention measures, seeking help from family and friends and recognition by hospital management were a significant supportive measure $(\mathrm{P}<0.001)$. Nurses and Midwives working directly with COVID-19 patients reported greater incidence of depression, anxiety and stress, similar to findings from previous research around the world. Therefore, efforts should be focused on developing and providing
\end{abstract}


counselling and other support services to mitigate the effects of COVID-19 and enhance psychological wellbeing for health professions.

\section{Keywords}

COVID-19 Pandemic, Nurses, Midwives, Depression, Anxiety and Stress

\section{Background}

Coronavirus (COVID-19) a viral outbreak was reported in Wuhan, Hubei Province, China in December 2019 [1]. The disease which was initially thought to be localized, rapidly spread to other parts of China and by end of March 2020, it had spread globally to more than 190 countries. At this time, it was estimated to have affected in excess of one million people and more than 50,000 deaths, among them nurses and midwives and other health providers. Due to the contagious nature of the disease, the fast rate at which it spread, and the number of people it affected within a short period of time, the WHO [2] declared COVID-19 an international public health emergency. Following the declaration, many countries rapidly implemented measures to limit human interaction to curb the spread of the disease. The measures employed ranged from limiting international and local travels, avoiding gathering, closing of schools, colleges and universities, encouraging non-essential workers to work from home to complete lock-down of cities and nations and encouraging people to stay home. Facing this critical situation, health care workers majority of whom are nurses and midwives are required to be at the front line to provide treatment and care for patients and clients in general and those with COVID-19, thereby risking not only contracting the disease but also developing psychological distress and other mental health symptoms [3].

Although every individual experiences anxiety at some moment in their life time in response to different stressors or traumatic events within the environment, nurses and midwives have an added risk of stress and anxiety due to the nature of their job. In addition, fear and anxiety related to contracting a deadly disease and the possibility of infecting family members can be overwhelming and cause strong emotions in nurses and midwives [4]. It has been theorized that during pandemics, nurses and midwives have worse mental health outcomes than medical doctors because these frontline workers have the highest risk of infection due to the amount of close, frequent contact they have with patients [5].

Inadequate or lack of personal protective equipment such as masks, gloves, and gowns may put nurses and midwives even at higher risk of contracting the infection and hence increasing their levels of anxiety. Nurses and midwives spend more time with patients than any other member of the health care team thereby, increasing their exposure to the disease. In addition, some nurses and midwives may have fewer years of work experience, which may make them feel 
less sure about themselves, and all these add up to the greater feelings of uncertainty and lack of control [5].

Literature alerts us that during pandemics, there are even more increased levels of stress among health care providers. A study conducted in 2012, three years after the SARS outbreak showed that health workers, feared infection which did happen to a number of them. They also felt stigmatized, isolated and worried about transmitting the infection to family and friends. Other SARS health workers reported feeling a lack of control and a desire to resign [5]. Therefore, nurses and midwives at the frontline of containing the COVID-19 outbreak may not just be risking their physical health, but their mental health as well [5].

Despite the above evidence, the situation among Zambian nurses and midwives is currently unknown. However, based on documented evidence, it is assumed that nurses and midwives in Zambia may be experiencing high levels of psychological distress such as depression, anxiety and insomnia due to COVID-19 pandemic if interventions are not urgently put in place, the nurses and midwives may find themselves in a mental health crisis.

It is with the above background in mind that the study sought to assess nurses' and midwives' levels of depression, anxiety, and stress, and explore their coping strategies while caring for patients with COVID-19.

\section{Materials and Methods}

\subsection{Design and Study Site}

A cross-sectional survey involving 187 nurses and midwives from selected health facilities in Lusaka and Chilanga District was conducted between July and December 2020 to assess the levels of depression, anxiety and stress among nurses and midwives working in both COVID-19 isolation centres and other health facilities. The nurses were drawn from Casualty, Outpatient Departments (OPD), Medical and Surgical wards, Intensive Care Units (ICUs) and COVID-19 Isolation and treatment Centres. The total sample size was calculated using the prevalence formula.

\subsection{Sampling}

Purposive sampling method was used to select the tertiary level hospitals, and isolation and treatment centres, while simple random technique was used to select first level Hospitals and health centres from which the study participants were drawn. In addition, nurses and midwives in the selected health facilities were selected using convenience sampling technique in order to get a sample of those who were directly dealing with COVID-19 patients and those mostly likely to deal with potential cases in OPDs, Medical and Surgical units and ICUs.

\subsection{Data Collection Procedures}

Upon gaining access to the health facility, the in-charge was requested to assist identify nurses and midwives to participate in the study. Those who meet the in- 
clusion criteria were then approached and asked if they were willing to participate. An information sheet explaining the nature and purpose of the study was given to the participants after which, those who were willing to participate were given an informed consent form to sign.

\subsection{Data Collection Tool}

The data was collected using Depression Anxiety and Stress Scale (DASS) 21 [6], and seven questions on social demographic characteristics. The DASS is a 21-item self-administered questionnaire designed to measure the emotional states; Depression, Anxiety and Stress. It contains three domains (Depression, Anxiety and Stress) with each consisting of seven items [7]. The DASS-21 has been validated as a reliable tool to identify symptoms in the three highlighted domains and for use in clinical and non-clinical samples. In addition, it has been found to possess well-established psychometric properties which reliably measure depression, anxiety and stress (at a Cronbach's alpha $0.91,0.84$ and 0.90 respectively), and has the ability to differentiate between depression, anxiety and stress [7] [8] [9].

\subsection{Ethical Considerations}

Ethical approval was obtained from the University of Zambia Biomedical Research Ethics Committee (UNZABREC). Permission to conduct the study was also sought from the National Health Research Authority (NHRA), while clearance to access health facilities that participated in the study was obtained from Lusaka District Health Office. On accessing the said facilities, permission was then obtained from the person in-charge who also assisted with the recruitment of eligible participants.

An information sheet outlining the nature and purpose of the study was provided to the participants. Subsequently, informed consent was obtained from those who expressed willingness to participate. Appropriate time was allowed for participants to synthesise the information before obtaining consent as recommended by [10].

The right to withdraw from participation if participants felt like, without any prejudice was upheld throughout the data collection process and participants were informed of their right prior to consenting. Confidentiality regarding information they were volunteering was assured and maintained. The tapes and notes were kept always locked and only accessible to the research team in line with Childress \& Beauchamp [11].

\subsection{Data Analysis}

The data was analysed using the Statistical Package for Social Sciences (SPSS) version 25.0 for the Windows platform (SPSS Inc., Chicago, IL, USA). Measures of central tendency were used to analyse demographic characteristics of the participants. The data collected on depression, anxiety and stress scores using the 
DASS were grouped into yes/no responses before conducting univariate analysis. DASS scores of $\geq 10, \geq 8, \geq 15$ in depression, anxiety and stress domains respectively are regarded as presence of the respective disorders as prescribed by the DASS manual [6].

In order to ensure representative findings for nurses and midwives, the study adjusted prevalence estimates by using sampling weights reflecting the size of the study population as a whole.

Univariate analysis has been performed on categorical and continuous variables in order to generate mean values, standard deviations (SD), frequencies (n) and proportion percentages (\%).

\section{Results}

A total of 187 nurses and midwives from selected health facilities in Lusaka and Chilanga districts participated in the study as highlighted in Table 1. Among the respondents accessed, the mean age was 30.1 (SD 9.05) years, and 66.36 percent of them were under 30 years of age. Most of the participants were female (84\%), with 58.3 percent of them married, while 50.84 percent had children. The mean work experience was 6.63 years (SD 4.75), and 54 percent had worked for less than five years. Among the 187 participants, 26.7 percent were working in outpatient departments.

About 22.5 percent of the respondents had varying levels of depression with 9.1 percent of them having severe depression (Table 2). Almost half of the respondents (52.4\%) had some COVD-19 related anxiety with 10.7 percent of them exhibiting severe anxiety. In terms of stress, 24.1 percent of the respondents had moderate levels of stress while 9.1 percent exhibited severe levels.

On cross tabulation, the results (Table 3) showed that 71.4 percent of respondents working in the COVID-19 isolation centres had severe anxiety compared to respondents in medical/surgical wards (18.4\%). This revealed a statistically significant association between workplace and COVID related anxiety $(\mathrm{P}=$ $\left.0.001, \mathrm{X}^{2}=45.951\right)$. Further a significant association $\left(\mathrm{P}=0.001, \mathrm{X}^{2}-46.134\right)$ was noted between stress levels and the ward one (Table 4). Depression (Table 5) was also noted to relate significantly with place one was working from $(\mathrm{P}=$ $0.001, \mathrm{X}^{2}=50.652$ ).

\section{Discussion}

To our knowledge, this is one of the first studies to look at depression, anxiety, and stress among nurses and midwives in Zambia during the COVID-19 pandemic. Nurses and midwives in selected health facilities in Chilanga and Lusaka districts of Zambia participated in this study.

\subsection{Depression among Nurses and Midwives}

The findings of the current study reveal that 22.5 percent of the respondents had varying levels of self-reported depression as revealed by the DASS 21 . Of this 
Table 1. Sociodemographic characteristics $(\mathrm{N}=187)$.

\begin{tabular}{|c|c|c|}
\hline Variable & $\mathbf{N}$ & $(\%)$ \\
\hline \multicolumn{3}{|l|}{ Gender } \\
\hline Male & 30 & 16 \\
\hline Female & 157 & 84 \\
\hline \multicolumn{3}{|l|}{ Marital status } \\
\hline Married & 109 & 58.3 \\
\hline Single & 72 & 38.5 \\
\hline Divorced & 1 & 0.5 \\
\hline Widowed & 5 & 2.7 \\
\hline \multicolumn{3}{|l|}{ Highest level qualification } \\
\hline High density & 25 & 13.4 \\
\hline Medium density & 124 & 66.3 \\
\hline Low density & 36 & 19.3 \\
\hline \multicolumn{3}{|l|}{ Highest level qualifications } \\
\hline Diploma/Certificate & 164 & 87.7 \\
\hline Bachelors & 21 & 11.2 \\
\hline Masters & 2 & 1.1 \\
\hline \multicolumn{3}{|l|}{ Current department } \\
\hline Outpatients & 50 & 26.7 \\
\hline Casualty & 16 & 8.6 \\
\hline Admission & 52 & 27.8 \\
\hline Medical/surgical & 38 & 20.3 \\
\hline COVID-19 isolation centre & 7 & 3.7 \\
\hline $\mathrm{MCH}$ & 22 & 11.8 \\
\hline Public Health & 2 & 1.1 \\
\hline \multicolumn{3}{|l|}{ Work experience } \\
\hline Less than 5 years & 101 & 54.0 \\
\hline $5-10$ years & 40 & 21.4 \\
\hline $10-20$ years & 25 & 13.4 \\
\hline Above 20 years & 19 & 10.2 \\
\hline
\end{tabular}

number, close to ten percent reported having severe depression related to COVID-19. This demonstrates that a significant number of nurses and midwives at the front line of the COVID-19 pandemic have significant levels of depression and collaborates with previous research evidence [3] [12] [13] [14] which generally suggest that nurses and midwives attending to clients with COVID-19 face an increased burden of mental health challenges compared with the general population. Aly et al. [15] affirm that healthcare workers fighting against the 
Table 2. Severity categories and scores of depression, anxiety and stress.

\begin{tabular}{cccc}
\hline Characteristic & Level & N & (\%) \\
\hline \multirow{3}{*}{ Depression } & Normal & 145 & 77.5 \\
& Mild & 13 & 7.0 \\
& Moderate & 12 & 6.4 \\
& Severe & 17 & 9.1 \\
\hline \multirow{3}{*}{ Anxiety } & Normal & 89 & 47.6 \\
& Mild & 28 & 15 \\
& Moderate & 50 & 26.6 \\
& Severe & 20 & 10.7 \\
\hline \multirow{2}{*}{ Stress } & Normal & 110 & 58.8 \\
& Mild & 16 & 8 \\
& Moderate & 45 & 24.1 \\
& Total & 187 & 100 \\
\hline
\end{tabular}

Table 3. Workplace in relation to anxiety.

\begin{tabular}{|c|c|c|c|c|c|c|}
\hline \multirow{2}{*}{$\begin{array}{l}\text { Workplace/ } \\
\text { Department }\end{array}$} & \multicolumn{5}{|c|}{ Anxiety levels } & \\
\hline & Normal & Mild & Moderate & Severe & Total & \\
\hline OPD & $28(56)$ & $8(16)$ & $9(18)$ & $5(10)$ & $50(26.7)$ & $\mathrm{P}=0.000$ \\
\hline Casualty & $11(68.8)$ & $0(0)$ & $3(18.8)$ & $2(12.5)$ & $16(8.5)$ & \\
\hline Admission & $23(44.2)$ & $10(19.2)$ & $16(30.8)$ & $3(5.8)$ & $52(27.8)$ & \\
\hline Medical/surgical & $18(47.4)$ & $2(5.3)$ & $11(28.9)$ & $7(18.4)$ & $38(20.3)$ & $\mathrm{X}^{2}=45.951$ \\
\hline $\begin{array}{l}\text { COVID-19 } \\
\text { isolation }\end{array}$ & $0(0)$ & $0(0)$ & $2(28.6)$ & $5(71.4)$ & $7(3.7)$ & \\
\hline $\mathrm{MCH}$ & $5(22.7)$ & $7(31.8)$ & $8(36.4)$ & $2(9.1)$ & $22(11.8)$ & \\
\hline Public Health & $1(50)$ & $0(0)$ & $1(50)$ & $0(0)$ & $2(1.1)$ & \\
\hline Total & $86(46)$ & $27(14.4)$ & $50(26.7)$ & $24(12.8)$ & $187(100)$ & \\
\hline
\end{tabular}

Table 4. Workplace in relation to stress.

\begin{tabular}{ccccccc}
\hline \multirow{2}{*}{$\begin{array}{c}\text { Workplace/ } \\
\text { Department }\end{array}$} & \multicolumn{5}{c}{ Anxiety levels } \\
\cline { 2 - 5 } & Normal & Mild & Moderate & Severe & Total & \\
\hline OPD & $29(58)$ & $5(10)$ & $12(24)$ & $4(8)$ & $50(26.7)$ & P $=0.000$ \\
Casualty & $9(56.3)$ & $2(12.5)$ & $3(18.8)$ & $2(12.5)$ & $16(8.6)$ & \\
Admission & $31(59.6)$ & $2(3.8)$ & $13(25)$ & $6(11.5)$ & $52(27.8)$ \\
Medical/surgical & $22(57.9)$ & $4(10.5)$ & $10(26.3)$ & $2(5.3)$ & $38(20.3)$ & $X^{2}=46.134$ \\
COVID-19 & $0(0)$ & $0(0)$ & $1(14.3)$ & $6(85.7)$ & $7(3.7)$ \\
isolation & $14(63.6)$ & $2(9.1)$ & $5(4.5)$ & $1(4.5)$ & $22(11.8)$ \\
MCH & $2(100)$ & $0(0)$ & $0(0)$ & $0(0)$ & $2(1.1)$ \\
Public Health & $107(57.2)$ & $15(8)$ & $44(23.5)$ & $21(11.2)$ & $187(100)$ \\
Total & $15(18)$ &
\end{tabular}


Table 5. Workplace in relation to depression.

\begin{tabular}{|c|c|c|c|c|c|c|}
\hline \multirow{2}{*}{$\begin{array}{l}\text { Workplace/ } \\
\text { Department }\end{array}$} & \multicolumn{4}{|c|}{ Anxiety levels } & \multirow[b]{2}{*}{ Total } & \\
\hline & Normal & Mild & Moderate & Severe & & \\
\hline OPD & $36(72)$ & $5(10)$ & $4(8)$ & $5(10)$ & $50(26.7)$ & $\mathrm{P}=0.0001$ \\
\hline Casualty & $14(87.5)$ & $0(0)$ & $1(0)$ & $1(0)$ & $16(8.6)$ & \\
\hline Admission & $44(84.6)$ & $3(5.8)$ & $3(5.8)$ & $2(3.8)$ & $52(27.8)$ & \\
\hline Medical/surgical & $32(84.2)$ & $2(5.3)$ & $3(7.9)$ & $1(2.6)$ & $38(20.3)$ & $X^{2}=50.652$ \\
\hline COVID-19 isolation & $0(0)$ & $0(0)$ & $2(28.6)$ & $5(71.4)$ & $7(3.7)$ & \\
\hline $\mathrm{MCH}$ & $13(59.1)$ & $2(9.1)$ & $4(18.2)$ & $3(13.6)$ & $22(11.8)$ & \\
\hline Public Health & $2(100)$ & $0(0)$ & $0(0)$ & $0(0)$ & $2(1.1)$ & \\
\hline Total & $141(75.4)$ & $12(6.4)$ & $17(9.1)$ & $17(9.1)$ & $187(100)$ & \\
\hline
\end{tabular}

COVID-19 pandemic are under tremendous pressure, which puts them at an increased risk of developing depression. According to him, approximately one-third to half of the nurses reported symptoms of depression.

The present study findings show slightly lower incidence of depression among health workers compared to studies from other countries. For instance, Aly et al. [15] reported 94 percent of participants showed mild to severe depression while El-Zoghby [16] records 50.4 percent. The discrepancy in prevalence of depression may be attributed to methodological limitations, including differences in tools used, sample size and modes of delivery of data collection tools. Notwithstanding these differences, the study was conducted towards the end of the first wave and part of the second wave when the numbers of COVID-19 were not as high as those in the third wave. With the current increase in new infections and deaths seen in the third wave, the rates of depression may actually be comparable to that seen in other studies.

The depression seen in nurses and midwives particularly women who were unmarried and worked for less than five years, may have a heavier workload and a higher chance of direct contact with COVID-19 patients. Working longer hours than usual, as well as working in fearful, stressful, and confined situations where they are constantly at risk of infection, may all contribute to developing depression. Furthermore, the separation from family members during periods of quarantine may also be a major source of depression seen among the respondents.

Therefore, mental health support for nurses and midwives is extremely critical during pandemics like the one being experienced currently.

\subsection{Anxiety Levels among Nurses and Midwives}

The present study findings show presence of COVID-19 related anxiety in 52.4 percent of the respondents. These findings are consistent with Lai et al. [3] and Khanal et al. [17] whose studies found a significant number of the frontline health care workers with some symptoms of anxiety. This high prevalence of an- 
xiety is a source of concern because Zambia's mental health services are significantly under-resourced [18], lack a formal, well defined mental health response plan, availability and accessibility of mental health services is nonexistent during the COVID-19 pandemic. This may impose negative consequences on the COVID-19 response by the health workers.

The study also found that all the nurses and midwives who worked in the COVID-19 treatment centres had COVID-19 related anxiety with levels ranging from moderate to severe. The results suggest that the type of department one operates from associates significantly with levels of anxiety $\left(\mathrm{P}=0.000, \mathrm{X}^{2}=\right.$ 45.951). These findings are in agreement with $\mathrm{Lu}$ et al. [19] who reported that those health workers who directly attended to patients with COVID-19 had higher levels of anxiety than those working in other hospital units. Similarly, Lai et al. [3] state that nurses in the frontline reported experiencing more severe symptom levels of anxiety compared to those working in other units. Most of the respondents in the present study were anxious regarding their safety and the safety of their families and reported psychological effects arising from reports of mortalities from COVID-19 infection. The results highlight the need for the Health sector other stake holders to monitor the mental health of nurses and midwives on the frontline of the COVID-19 pandemic, not limited to regulating their workload, giving emotional support, and recognition of their efforts. In addition, further research is required to explore nurses copying strategies in view of the present findings.

\subsection{Stress Levels among Nurses and Midwives}

In the present study, nearly half of the nurses and midwives (42.2\%) had varying levels of stress. The findings affirm and extend several previous studies [20] [21] [3] that show that front-line medical staff experienced emotional stress during the previous epidemics although their extent differed. For instance, Shechter et al. [22] reported 57 percent positive screens for psychological stress while Aly et al. [15] noted that 98.5 percent of respondents showed moderate to severe stress. Staff in direct contact with patients had higher levels of both acute or post-traumatic stress and psychological distress [23]. This supports our finding that workplace or department one is working from is significantly related to the level of stress $\left(\mathrm{P}=0.001, \mathrm{X}^{2}-46.134\right)$.

Similar to other scholars, we also found that respondents who were women [24], younger [25] [26] [27], were more vulnerable to stress. This was linked to social isolation and the fear of infecting their family or having an infected family member.

\section{Conclusion}

COVID-19 has caused considerable health problems to the global community in different ways. Health professionals, especially nurses and midwives have been strained like never before, leading to unprecedented reports of mental distress. 
The prevalence of Depression, Anxiety and Stress among nurses and midwives at the front line of the COVID-19 pandemic is evident in the present study. While the prevalence of Depression appears to be lower in comparison to previous studies, nurses and midwives have reported higher levels of anxiety and stress albeit at varying levels. In order to manage the risk factors, health authorities should consider responsive interventions which may include training and mental health protective measures for all frontline health workers and not only those working in the COVID-19 isolation and treatment centres. Additionally, Zambia's health care authorities can consider telemedicine, given the wide-spread adoption of smartphones, to help remove barriers to accessing care for mental health. This can be done through the provision of Hotline numbers for nurses and midwives to access mental health services anytime they feel stressed or anxious. It is envisaged that this can alleviate the psychological trauma that nurses and midwives may be experiencing during this pandemic.

\section{Relevance for Clinical Practice}

This study provides insight into psychological wellbeing of nurses and midwives in Zambia during the COVID-19 pandemic. The presence of depression, anxiety and stress among the front-line health workers is a source of concern as it may affect provision of quality care to patients. The detailed and accurate body of knowledge generated will help hospitals design tailor made stress alleviating programs for nurses and midwives.

\section{Authorship Statement}

Lonia Mwape and Patricia Katowa-Mukwato conceptualized the study. Esther Chirwa, Mavis Mtonga and Kestone Lyambai performed the field data collection. Kestone Lyambai working closely with Esther Chirwa performed the data analysis. All the authors participated in the drafting of the manuscript, reviewed it, and accepted the final version before submission for publication.

\section{Acknowledgements}

The authors would like to thank all the nurses and midwives who participated in the study.

\section{Funding Information}

No external funding was received for this project.

\section{Conflicts of Interest}

Authors declare no financial or other potential conflict of interest.

\section{References}

[1] Minh Duc, N., Duc Ha, H., Anh Tuan, T., Lien Bang, M.T., Hong Duc, P. and Minh Thong, P. (2020) From First COVID-19 Case to Current Outbreak: A Vietnamese Report. Electronic Journal of General Medicine, 17, em208. 
https://doi.org/10.29333/ejgm/7867

[2] World Health Organisation WHO (2020) Report of the WHO-China Joint Mission on Coronavirus Disease 2019 (COVID-19). World Health Organisation, Geneva.

[3] Lai, J., Ma, S., Wang, Y., Cai, Z., Hu, J. and Wei, N. (2020) Factors Associated with Mental Health Outcomes among Health Care Workers Exposed to Coronavirus Disease 2019. JAMA Network Open, 3, e203976.

https://doi.org/10.1001/jamanetworkopen.2020.3976

[4] Wetsman, N. (2020) Health Care Workers Are at High Risk of Catching COVID-19. Vox Media Inc., Washington DC.

[5] Feder, S. (2020) Chinese Nurses Report Anxiety and Depression during Corona Virus Outbreak. Insider. https://www.insider.com

[6] Lovibond, P.F. and Lovibond, S.H. (1995) The Structure of Negative Emotional States: Comparison of the Depression Anxiety Stress Scales (DASS) with the Beck Depression and Anxiety Inventories. Behaviour Research and Therapy, 33, 335-343. https://doi.org/10.1016/0005-7967(94)00075-U

[7] Cheung, T. and Yip, P.S. (2015) Depression, Anxiety and Symptoms of Stress among Hong Kong Nurses: A Cross-Sectional Study. International Journal of Environmental Research and Public Health, 12, 11072-11100.

https://doi.org/10.3390/ijerph120911072

[8] Crawford, J.R. and Henry, J.D. (2003) The Depression Anxiety Stress Scales (DASS): Normative Data and Latent Structure in a Large Non-Clinical Sample. British Journal of Clinical Psychology, 42, 111-131. https://doi.org/10.1348/014466503321903544

[9] Osman, A., Wong, J.L., Bagge, C.L., Freedenthal, S., Gutierrez, P.M. and Lozano, G. (2012) The Depression Anxiety Stress Scales-21 (DASS-21): Further Examination of Dimensions, Scale Reliability, and Correlates. Journal of Clinical Psychology, 68, 1322-1338. https://doi.org/10.1002/jclp.21908

[10] Willig, C. (2000) Introducing Qualitative Research in Psychology: Adventures in Theory and Method. Open University Press, Buckingham.

[11] Childress, J.F. and Beauchamp, T.L. (1994) Principles of Biomedical Ethics. Oxford University Press, Oxford.

[12] Shah, J., Monroe-Wise, A., Talib, Z., Nabiswa, A., Said, M., Abeid, A., Ali Mohamed, M., Mohamed, S. and Ali, S.K. (2021) Mental Health Disorders among Healthcare Workers during the COVID-19 Pandemic: A Cross-Sectional Survey from Three Major Hospitals in Kenya. BMJ Open, 11, e050316. https://doi.org/10.1136/bmjopen-2021-050316

[13] Sigdel, A., Bista, A., Bhattarai, N., Pun, B.C., Giri, G., Marqusee, H. and Thapa, S. (2020) Depression, Anxiety and Depression-Anxiety Comorbidity amid COVID-19 Pandemic: An Online Survey Conducted during Lockdown in Nepal. https://doi.org/10.1101/2020.04.30.20086926

[14] Nwanonyiri, D., Ogiehor-Enoma, G., Iwu, E. and Nwaneri, T. (2021) Helping Nurses Cope with COVID-19 Pandemic: Evaluating Support Programs. Open Journal of Nursing, 11, 65-74. https://doi.org/10.4236/ojn.2021.112007

[15] Aly, H.M., Nemr, N.A., Kishk, R.M. and Elsaid, N.M. (2021) Stress, Anxiety and Depression among Healthcare Workers Facing COVID-19 Pandemic in Egypt: A Cross-Sectional Online-Based Study. BMJ Open, 11, e045281.

https://doi.org/10.1136/bmjopen-2020-045281

[16] El-Zoghby, S.M., Salama, M., et al. (2020) Impact of the COVID-19 Pandemic on Mental Health and Social Support among Adult Egyptians. Journal of Community Health, 45, 689-695. https://doi.org/10.1007/s10900-020-00853-5 
[17] Khanal, P., Devkota, N., Dahal, M., Paudel, K. and Joshi, D. (2020) Mental Health Impacts among Health Workers during COVID-19 in a Low Resource Setting: A Cross-Sectional Survey from Nepal. Global Health, 16, Article No. 89. https://doi.org/10.1186/s12992-020-00621-Z

[18] Mwape, L., Mweemba, P. and Kasonde, J. (2012) Strengthening the Health System to Enhance Mental Health in Zambia: A Policy Brief. International Journal of Technology Assessment in Health Care, 28, 294-300.

https://doi.org/10.1017/S0266462312000347

[19] Lu, W., Wang, H., Lin, Y. and Li, L. (2020) Psychological Status of Medical Workforce during the COVID-19 Pandemic: A Cross-Sectional Study. Psychiatry Research, 288, 112936-112936. https://doi.org/10.1016/j.psychres.2020.112936

[20] Cai, H., Tu, B., Ma, J., Chen, L., Fu, L., Jiang, Y. and Zhuang, Q. (2020) Psychological Impact and Coping Strategies of Frontline Medical Staff in Hunan between January and March 2020 during the Outbreak of Coronavirus Disease 2019 (COVID) in Hubei, China. Medical Science Monitor, 26, e924171-1. https://doi.org/10.12659/MSM.924171

[21] Chen, Q., Liang, M., Li, Y., Guo, J., Fei, D., Wang, L., He, L., Sheng, C., Cai, Y., Li, X., Wang, J. and Zhang, Z. (2020) Mental Health Care for Medical Staff in China during the COVID-19 Outbreak. The Lancet Psychiatry, 7, e15-e16. https://doi.org/10.1016/S2215-0366(20)30078-X

[22] Shechter, A., Diaz, F., Moise, N., Anstey, D.E., Ye, S., Agarwal, S., Birk, J.L., Brodie, D., Cannone, D.E., Chang, B., Claassen, J., Cornelius, T., Derby, L., Dong, M., Givens, R.C., Hochman, B., Homma, S., Kronish, I.M., Lee, S., Manzano, W., Abdalla, M., et al. (2020) Psychological Distress, Coping Behaviors, and Preferences for Support among New York Healthcare Workers during the COVID-19 Pandemic. General Hospital Psychiatry, 66, 1-8. https://doi.org/10.1016/j.genhosppsych.2020.06.007

[23] Kisely, S., Warren, N., McMahon, L., Dalais, C., Henry, I. and Siskind, D. (2020) Occurrence, Prevention, and Management of the Psychological Effects of Emerging Virus Outbreaks on Healthcare Workers: Rapid Review and Meta-Analysis. BMJ, 369, m1642. https://doi.org/10.1136/bmj.m1642

[24] da Silva, M.L., Rocha, R.S.B., Buheji, M., Jahrami, H. and Cunha, K.C. (2021) A Systematic Review of the Prevalence of Anxiety Symptoms during Coronavirus Epidemics. Journal of Health Psychology, 26, 115-125. https://doi.org/10.1177/1359105320951620

[25] Browning, M.H.E.M., Larson, L.R., Sharaievska, I., Rigolon, A., McAnirlin, O., Mullenbach, L., Cloutier, S., Vu, T.M., Thomsen, J., Reigner, N., Metcalf, E.C., D’Antonio, A., Helbich, M., Bratman, G.N. and Alvarez, H.O. (2021) Psychological Impacts from COVID-19 among University Students: Risk Factors across Seven States in the United States. PLOS ONE, 16, e0245327. https://doi.org/10.1371/journal.pone.0245327

[26] Zheng, S., Fan, J., Yu, F., Feng, B., Lou, B., Zou, Q., Liang, T., et al. (2020) Viral Load Dynamics and Disease Severity in Patients Infected with SARS-CoV-2 in Zhejiang Province, China, January-March 2020: Retrospective Cohort Study. BMJ, 369, m1443. https://doi.org/10.1136/bmj.m1443

[27] Que, J., Shi, L., Deng, J., Liu, J., Zhang, L., Wu, S., Gong, Y., Huang, W., Yuan, K., Yan, W., Sun, Y., Ran, M., Bao, Y. and Lu, L. (2020) Psychological Impact of the COVID-19 Pandemic on Healthcare Workers: A Cross-Sectional Study in China. General Psychiatry, 33, e100259. https://doi.org/10.1136/gpsych-2020-100259 